JETE : VOL 2 NO 2 2021* E-ISSN : 2745-9888* P-ISSN : 2745-9896

Journal of Education and Teaching

http://ejournal.uin-suska.ac.id/index.php/JETE

\title{
PENERAPAN MODEL PEMBELAJARAN KOOPERATIF TIPE NUMBERED HEAD TOGETHER UNTUK MENINGKATKAN HASIL BELAJAR MATEMATIKA SISWA KELAS VII SMP NEGERI 3 TAPUNG HILIR
}

\author{
Agus Hadi Muswanto ${ }^{1}$ \\ Sekolah Menengah Pertama Negeri 3 Tapung Hilir $^{1}$ \\ Email: agushadimuswanto@gmail.com ${ }^{1}$ \\ Received: 30 Oktober 2019; Accepted 12 Agustus 2021; Published 1 September 2021
}

Ed 2021; 2 (2): 177-187

\begin{abstract}
ABSTRAK
Tujuan penelitian ini adalah untuk meningkatkan hasil belajar matematika siswa kelas VII SMP Negeri 3 Tapung Hilir. Rumusan masalahnya adalah apakah penerapan model pembelajaran kooperatif tipe Numbered Head Together dapat meningkatkan hasil belajar matematika siswa kelas VII SMP Negeri 3 Tapung Hilir? Hipotesis dari penelitian ini adalah : jika diterapkan model pembelajaran kooperatif tipe Numbered Head Together maka dapat meningkatkan hasil belajar matematika siswa kelas VII SMP Negeri 3 Tapung Hilir. Penelitian ini dilakukan sebanyak III suklus. Persentase aktivitas guru pada siklus I adalah 66,7\% (kategori : baik), pada siklus II adalah 83,3\% (kategori : amat baik) dan pada silus III adalah 93,8\% (kategori: amat baik). Sedangkan persentase aktivitas belajar siswa pada siklus I adalah 51,4\% (kategori : cukup), pada siklus II adalah 64,9\% (kategori : baik) dan pada siklus III adalah 83,9\% (kategori : amat baik). Berdasarkan analisis data dan pembahasan penelitian. Rerata hasil belajar siswa mengalami peningkatan. Rerata hasil belajar siswa pada skor dasar adalah 60,1, pada siklus I 69,2, pada siklus II 75,2 dan pada siklus III 84,3. Berdasarkan hasil penelitian maka dapat disimpulkan bahwa penerapan model pembelajaran kooperatif tipe Numbered Head Together dapat meningkatkan hasil belajar matematika siswa kelas VII SMP Negeri 3 tapung Hilir.
\end{abstract}

Kata Kunci: Model Pembelajaran Kooperatif Tipe Numbered Head Together, Hasil Belajar Matematika

\section{PENERAPAN MODEL PEMBELAJARAN KOOPERATIF TIPE NUMBERED HEAD TOGETHER UNTUK MENINGKATKAN HASIL BELAJAR MATEMATIKA SISWA KELAS VII SMP NEGERI 3 TAPUNG HILIR}

\begin{abstract}
The purpose of this study was to improve mathematics learning outcomes of Grade VII students of SMP Negeri 3 Tapung Hilir. The formulation of the problem is whether the application of the cooperative learning model type Numbered Head Together can improve mathematics learning outcomes of Grade VII students of SMP Negeri 3 Tapung Hilir? The hypothesis of this study is: if
\end{abstract}


the cooperative learning model Numbered Head Together is applied, it can improve the mathematics learning outcomes of Grade VII students of SMP Negeri 3 Tapung Hilir. This research was carried out as much as III success. The percentage of teacher activity in the first cycle was 66.7\% (category: good), in the second cycle was $83.3 \%$ (category: very good) and in the third cycle was $93.8 \%$ (category: very good). While the percentage of student learning activities in the first cycle was 51.4\% (category: enough), in the second cycle was $64.9 \%$ (category: good) and in the third cycle was $83.9 \%$ (category: very good). Based on data analysis and research discussion. The mean student learning outcomes have increased. The mean student learning outcomes on the base score were 60.1, in the first cycle 69.2, in the second cycle 75.2 and in the third cycle 84.3. Based on the results of the research it can be concluded that the application of the Numbered Head Together cooperative learning model can improve mathematics learning outcomes of Grade VII students of SMP Negeri 3 Tapung Hilir.

Keywords: Cooperative Learning Model Type Numbered Head Together, Mathematics Learning Outcomes

\section{PENDAHULUAN}

Matematika merupakan ilmu pengetahuan yang mempelajari struktur yang abstrak dan pola hubungan yang ada di dalamnya. Ini berarti bahwa belajar matematika pada hakekatnya adalah belajar konsep, struktur konsep dan mencari hubungan anatr konsep dan strukturnya. Sistem matematika berisikan model-model yang dapat digunakan untuk mengatasi persoalan-persoalan nyata. Manfaat lain yang menonjol adalah matematika dapat membentuk pola pikir orang yang mempelajarinya. (Depdiknas 2006:1)

Matematika adalah salah satu mata pelajaran yang diajarkan di sekolah mulai dari SD, SMP, SMA, bahkan sampai di perguruan tinggi. matematika memiliki peranan penting dalam mengembangkan kemampuan berpikir siswa, dengan demikian sudah seharusnya setiap siswa diharapkan dapat menguasai matematika dan mencapai hasil belajar matematika dengan baik.

Berdasarkan hasil observasi dan wawancara peneliti dengan guru matematika kelas VII SMP Negeri 3 Tapung Hilir dinyatakan hasil belajar matematika tergolong rendah, hal ini dapat dilihat dari Kriteria Ketuntasan Minimum (KKM) yang ditetapkan oleh sekolah yaitu 70. Dari 37 orang siswa kelas VII , hanya yang mencapai KKM adalah sebanyak 26 orang siswa $(70,3 \%)$, dan 11 orang siswa $(29,7 \%)$ belum mencapai KKM, dengan rata-rata hasil belajar matematika 60,1.

Rendahnya hasil belajar matematika siswa disebabkan oleh 1) pada umumnya dalam mengajar guru hanya menggunakan metode ceramah, 2) guru tidak pernah melakukan metode diskusi di dalam kelas, 3) guru jarang melibatkan siswa sepenuhnya dalam proses pembelajaran. Sehingga anak yang mempunyai kemampuan akadamis tinggi saja yang aktif sedangkan anak yang mempunyi kemampuan akademis rendah bersifat pasif, tidak memperhatikan penjelasan dari guru, tidak mau bertanya kepada siswa yang lebih pandai dan siswa yang lebih pandai juga tidak bisa mengajari siswa yang kurang pandai sebab tidak ada metode diskusi yang digunakan oleh guru.

Untuk meningkatkan hasil belajar matematika siswa, upaya yang dilakukan guru adalah menggunakan strategi yang tepat, sebab dengan menggunakan strategi yang tepat maka akan dapat menunjang keberhasilan siswa dalam proses pembelajaran. Dari uraian di atas diharapkan dalam upaya meningkatkan hasil belajar siswa dalam mata pelajaran 
matematika perlu adanya strategi pengajaran yang melibatkan semua siswa menjadi aktif dan siap dalam mengikuti proses pembelajaran. Salah satu caranya adalah dengan menerapkan model pembelajaran kooperatif tipe Numbered Head Together (NHT) di kelas VII SMP Negeri 3 Tapung Hilir.

Menurut Ahmadi dkk (2011:60) Kelebihan dari model Cooperative Learning tipe Numbered Heads together (NHT) yaitu: Setiap siswa menjadi siap semua, dapat melakukan diskusi dengan sungguh-sungguh dan Siswa yang pandai dapat mengajari siswa yang kurang pandai.

\section{METODOLOGI}

Jenis penelitian ini adalah penelitian tindakan kelas. Penelitian tindakan kelas adalah penelitian yang dilakukkan dengan tujuan memperbaiki suatu mutu praktek pembelajaran dikelasnya (Arikunto,dkk, 2007).

Penelitian ini bersifat kolaboratif yaitu perangkat pembelajaran dirancang oleh peneliti, pelaksanaan tindakan dilakukan peneliti, dan guru berperan sebagai pengamat selama proses pembelajaran. Tindakan yang akan dilakukan adalah penerapan model kooperatif tipe Numbered Head Together (NHT) untuk meningkatkan hasil belajar matematika siswa kelas VII SMP Negeri 3 Tapung Hilir.

Penelitian tindakan secara garis besar terdapat empat tahap yang lazim, yaitu : (1) perencanaan, (2) pelaksanaan, (3) pengamatan, (4) refleksi (Arikunto, dkk 2007:16)

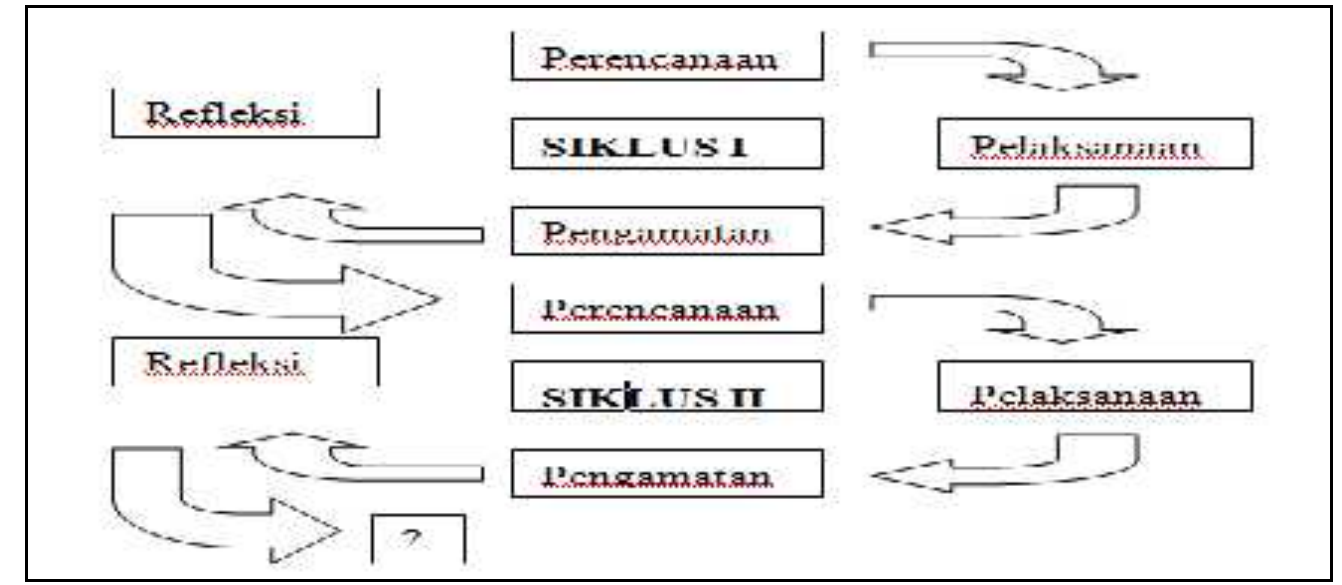

Gambar 1. Gambar Penelitian Tindakan Kelas (Arikunto, 2008:16)

Masing-masing komponen pada setiap siklus dalam penelitian ini berisikan:

1. Perencanaan

Pada tahap perencanaan peneliti menyiapkan perangkat pembelajaran: silabus, rencana pelaksanaan pembelajaran (RPP), lembar kerja siswa (LKS), serta mempersiapkan lembar pengamatan.

2. Pelaksanaan

Pelaksanaan merupakan implementasi dari tahap perencanaan dan proses memperbaiki dan meningkat kankegiatan yang akan dilakukan yang sesuai dengan model pembelajaran kooperatif tipe Numbered Head Together (NHT).

3. Pengamatan 
Pengamatan dilakukan bersamaan waktunya dengan pelaksanaan tindakan yang dilakukan oleh guru atau guru lain yang bekerja sama dalam penelitian ini dengan menggunakan lembar observasi/pengamatan. Mengamati hasil atau dampak dari tindakan yang dilaksanakan, Tujuannya untuk mengetahui apakah terlaksana model yang digunakan dalam proses pembelajaran dan mengetahui kekurangan-kekurangan yang dialami saat pelaksanaan tindakan.

4. Refleksi

Peneliti mengkaji, melihat dan mempertimbangkan atas hasil dari tindakan yang telah berlangsung. Tujuannya untuk mengetahui kekuatan dan kelemahan dari tindakan yang dilakukan untuk dapat diperbaiki pada siklus berikutnya.

Perangkat Pembelajaran yang digunakan pada penelitian ini adalah sebagai berikut:

a. Silabus

Silabus bermanfaat sebagai pedoman sumber pokok dalam pengembangan pembelajaran lebih lanjut, mulai dari pembuatan rencana pembelajaran, pengolahan kegiatan pembelajaran, dan pengembangan sistem penilaian.Silabus disusun berdasarkan prinsip yang berorientasi pada pencapaian kompetensi, yang memuat : identitas sekolah, standar kompetensi, kompetensi dasar, materi pokok, kegiatan pembelajaran, indikator, penilaian yang meliputi teknik penilaian, bentuk instrument, dan contoh instrument, alokasi waktu, dan sumber.

b. Rencana Pelaksanaan Pembelajaran (RPP)

Rencana Pelaksanaan Pembelajaran (RPP) tentang pembelajaran kooperatif tipe Numbered Head Together (NHT) dalam pembelajaran matematika disusun secara sistematis yang berisikan : standar kompetensi, kompetensi dasar, indikator, sumber pembelajaran. Kegiatan pembelajaran diawali dengan pendahuluan, kegiatan inti, dan penutup yang berpedoman pada langkah-langkah pembelajaran kooperatif tipe Numbered Head Together (NHT).

c. Lembar Kerja Siswa (LKS)

Lembar Kerja Siswa berisi, tujuan dan kegiatan yang berisi langkah-langkah kegiatan atau petunjuk kerja yang harus dikerjakan oleh siswa sebagai bentuk pemahaman terhadap materi pelajaran.

Penelitian ini dilakukan pada semester ganjil Tahun Pelajaran 2019/2020. Penelitian bertempat di SMP Negeri 3 Tapung Hilir JL. Dt. Penghulu Besar No. 125 Kota Garo Kec. Tapung Hilir Kab. Kampar. Subjek penelitian ini adalah siswa kelas VII SMP Negeri 3 Tapung Hilir dengan jumlah 37 orang siswa, yang terdiri dari 26 orang siswa laki-laki dan 11 orang siswa perempuan dimana siswa tersebut memiliki kemampuan yang heterogen.

Data yang dikumpulkan pada penelitian ini adalah data aktivitas guru dan siswa selama proses pembelajaran dan data tentang hasil belajar matematika siswa setelah proses pembelajaran.

a. Lembar observasi aktivitas guru dan siswa

Lembar pengamatan guru berisi aktivitas yang diamati yaitu dari aspek siswa dan aktivitas dari aspek guru yang disesuaikan dengan tahapan pembelajaran model kooperatif tipe Numbered Head Together (NHT).

b. Tes hasil belajar matematika

Data tentang hasil belajar matematika siswa setelah proses pembelajaran dikumpulkan dengan menggunakan tes hasil belajar, selanjutnya data tes hasil belajar 
tersebut dianalisis untuk perbaikan yang tujuannnya adalah meningkatkan hasil belajar. Tes hasil beajar siswa berupa tes individu secara tertulis yang berupa nilai ulangan yang dilaksanakan pada akhir pelajaran.

Teknik yang digunakan untuk mengumpulkan data dalam penelitian ini adalah teknik pengamatan, teknik tes dan teknik dokumentasi.

d. Teknik pengamatan

Teknik pengamatan ini menggunakan lembar pengamatan yang dilakukan peneliti untuk mengamati seluruh kegiatan yang berlangsung dari aktifitas guru dan siswa, mulai dari awal pembelajaran sampai proses pembelajaran berakhir.

e. Teknik tes

Teknik tes yang digunakan dalam penelitian ini adalah tes tertulis, tes tertulis bertujuan untuk mengetahui peningkatan hasil belajar matematika siswa. Tes hasil belajar berupa UH siklus I, UH siklus II dan UH siklus III. Pemberian tes hasil belajar ini dilakukan setelah pembelajaran melalui penerapan model Pembelajaran kooperatif tipe Numbered Head Together (NHT) ini berakhir.

f. Teknik dokumentasi

Teknik dokumentasi yang digunakan oleh peneliti dalam penelitian ini adalah pengumpulan nilai - nilai siswa kelas VII SMP Negeri 3 Tapung Hilir dari hasil nilai ulangan siswa dan foto yang dikumpulkan peneliti saat tindakan berlangsung.

Subjek penelitian dalam penelitian tindakan kelas ini adalah siswa kelas 5 SDN 018 Gerbang Sari Kec.Tapung Hilir. Jumlah siswa yang diteliti sebanyak 20 siswa yang terdiri dari 12 siswa dan 8 siswi. Peneliti mengambil subjek penelitian di kelas 5 karena pembelajaran soal cerita tentang satuan waktu merupakan permasalahan yang terdapat pada siswa kelas 5 SDN 018 Gerbang Sari Kec.Tapung Hilir.

Teknik analisis data dalam penelitian ini dilakukan dengan menggunakan teknik analisis deskriptif yaitu untuk menggambarkan data aktivitas guru dan siswa selama proses pembelajaran berlangsung dan data ketercapaian KKM. (Syahrilfiddin dkk, 2011:114)

g. Analisis data aktivitas guru dan siswa

Analisis data tentang aktivitas guru dan siswa didasarkan pada hasil yang diperoleh dari lembar pengamatan yang diambil pada saat proses pembelajaran berlangsung dengan melihat kesesuaian perencanaan dan pelaksanaan tindakan. Data tentang aktivitas guru dan siswa dalam proses pembelajaran berdasarkan lembar pengamatan yang dianalisis dengan cara menetukan rata - rata yang diperoleh.

Analisis data untuk aktivitas guru dan siswa menggunakan format checklist yang dilakukan dengan cara penskoran, kemudian hasil penskoran dihitung persentase aktivitasnya yaitu dengan membandingkan skor aktivitas yang diperoleh dengan skor aktivitas ideal, dengan rumus sebagai berikut :
$N R=\frac{J S}{S M} \times 100 \%$
( Dalam Syahrilfuddin dkk, $2011: 114$ )
Keterangan :
$\mathrm{NR}=$ Persentase rata - rata aktivitas (guru/siswa)
JS = Jumlah skor aktivitas yang dilakukan
$\mathrm{SM}=$ Skor maksimal yang didapat dari aktivitas guru/siswa 
Tabel 3.1

\section{Interval dan Kategori Aktifitas Guru dan Siswa}

\begin{tabular}{|l|l|}
\hline Persentase Interval & Kategori \\
\hline $81 \%-100 \%$ & Amat Baik \\
\hline $61 \%-80 \%$ & Baik \\
\hline $51 \%-60 \%$ & Cukup \\
\hline$\leq 50 \%$ & Kurang \\
\hline
\end{tabular}

Sumber (Syahrilfuddin dkk, 2011:115)

h. Analisis hasil belajar Matematika siswa

a) Ketuntasan Individu

Ketuntasan hasil belajar Matematika dapat dilihat dari setiap akhir pertemuan (ulangan siklus). Siswa dikatakan tuntas apabila siswa telah mencapai nilai KKM yang ditetapkan oleh SMP Negeri 3 Tapung Hilir yaitu 70. Hasil yang dicapai setiap siswa dihitung dari persentase jawaban yang benar.

Ketuntasan individu dapat dihitung dengan rumus :

$S=\frac{K}{N} x 100$

(Dalam Purwanto 2008 : 112)

Keterangan :

b) Ketuntasan Klasikal

$\mathrm{S} \quad=$ Nilai yang diharapkan (dicari)

$\mathrm{R}=$ Jumlah skor dari item atau soal yang dijawab benar

$\mathrm{N} \quad=$ Skor maksimum dari tes tersebut

Menurut Mulyasa suatu kelas dikatakan tuntas belajarnya (ketuntasan klasikal) apabila dalam kelas $\geq 75 \%$ dari seluruh siswa mencapai KKM yang telah ditentukan.

Untuk menentukan ketuntasan klasikal menggunakan rumus :

$\boldsymbol{P K}=\frac{S T}{N} \boldsymbol{x} \mathbf{1 0 0 \%} \quad$ Purwanto (dalam Syahrilfuddin 2011: 116)

Keterangan :

$$
\begin{array}{ll}
\mathrm{PK} & =\text { Ketuntasan klasikal } \\
\mathrm{ST} & =\text { Jumlah siswa yang tuntas } \\
\mathrm{N} & =\text { Jumlah siswa seluruhnya }
\end{array}
$$

c) Rata-rata hasil belajar matematika

Untuk mengetahui nilai rata-rata hasil belajar matematika maka dapat dilakukan dengan cara membandingkan jumlah nilai seluruh siswa dengan jumlah seluruh siswa.

$$
\bar{X}=\frac{\sum X \bar{i}}{\boldsymbol{n}} \text { (dalam Riduwan, dkk. 2011:38) }
$$

Keterangan $: \bar{X}=$ mean/rata - rata hasil belajar seluruh siswa

$\sum \boldsymbol{X} \boldsymbol{i}=$ jumlah tiap data/jumlah nilai seluruh siswa

d) Peningkatan Hasil Belajar

$$
=\text { jumlah data/jumlah seluruh siswa }
$$

Peningkatan hasil belajar dianalisis dengan menggunakan rumus presentase sebagai berikut. 


$$
\mathrm{P}=\frac{\text { Poserate }- \text { baserate }}{\text { Baserate }} \times 100 \% \quad \text { (Zainal Aqib,dkk 2011:53) }
$$

Keterangan:

$\mathrm{P} \quad$ : Persentase peningkatan

Postrate : Nilai rata-rata sesudah tindakan

Baserate : Nilai rata-rata sebelum tindakan

e) Penghargaan kelompok

Tingkat penghargaan kelompok diambil dari hasil tes yang telah diberikan setelah materi kelompok. Skor individu setiap kelompok memberi sumbangan pada kelompok berdasarkan rentang skor yang diperoleh setelah tes akhir. Kriteria sumbangan skor terhadap kelompok terlihat pada tebel berikut:

Tabel 3.2

Perhitingan Perkembangan Skor Individu

\begin{tabular}{|l|l|l|}
\hline No & Nilai tes & Skor Perkembangan \\
\hline 1 & Lebih dari 10 poin dibawah skor dasar & 0 poin \\
\hline 2 & 10 poin sampai 1 poin di bawah skor dasar & 10 poin \\
\hline 3 & Skor nol sampai 10 poin di atas skor dasar & 20 poin \\
\hline 4 & Lebih dari 10 poin di atas skor dasar & 30 poin \\
\hline 5 & $\begin{array}{l}\text { Pekerjaan sempurna (tidak memperhatikan skor } \\
\text { dasar) }\end{array}$ & 30 poin \\
\hline
\end{tabular}

Sumber: Rusman (2011:216)

Kemudian untuk mengetahui bagaimana tingkat penghargaan yang akan diberikan terhadap kelompok yang berprestasi perlu adanya kriteria sebagaimana dijelaskanpada tabel berikut:

Tabel 3.3

Perhitungan perkembangan Skor Kelompok

\begin{tabular}{|l|l|l|}
\hline No & Rata-RataSkor & Kualifikasi \\
\hline 1 & $0 \leq \mathrm{N} \leq 5$ & - \\
\hline 2 & $6 \leq \mathrm{N} \leq 15$ & Tim yang Baik (Good Team) \\
\hline 3 & $16 \leq \mathrm{N} \leq 20$ & Tim yang Baik Sekali ( Great Team ) \\
\hline 4 & $21 \leq \mathrm{N} \leq 30$ & Tim yang Istimewa ( Super team ) \\
\hline
\end{tabular}

Sumber: Rusman (2011:216).

\section{HASIL DAN PEMBAHASAN}

Hasil penelitian ini yang dilakukan diperoleh nilai 43-51 dengan frekuensi 1 (5\%), nilai 5260 dengan frekuensi 2 (10\%), nilai 61-69 dengan frekuensi 1 (5\%), nilai 70-78 dengan frekuensi 4 (20\%), nilai 79-87 dengan frekuensi 6 (30\%), nilai 88-96 dengan frekuensi 5 (25\%), nilai 97-100 dengan frekuensi 1 (5\%). Di bawah ini merupakan grafik distribusi data nilai berdasarkan hasil kemampuan siswa yaitu sebagai berikut: Di bawah ini merupakan tabel dan grafik distribusi data nilai berdasarkan hasil kemampuan siswa yaitu sebagai berikut: 
Tabel 1. Distribusi Frekuensi Data Nilai Siklus I

\begin{tabular}{|c|c|c|c|}
\hline No & INTERVAL & FREKUENSI & PERSENTASE \\
\hline 1 & $43-51$ & 1 & $5 \%$ \\
\hline 2 & $52-60$ & 2 & $10 \%$ \\
\hline 3 & $61-69$ & 1 & $5 \%$ \\
\hline 4 & $70-78$ & 4 & $20 \%$ \\
\hline 5 & $79-87$ & 6 & $30 \%$ \\
\hline 6 & $88-96$ & 5 & $25 \%$ \\
\hline 7 & $97-100$ & 1 & $5 \%$ \\
\hline \multicolumn{2}{|c|}{ JUMLAH } & $\mathbf{2 0}$ & $\mathbf{1 0 0 \%}$ \\
\hline
\end{tabular}

Manakala hasil tes secara grafik unjuk kerja siklus 1 dapat dilihat dibawah ini:

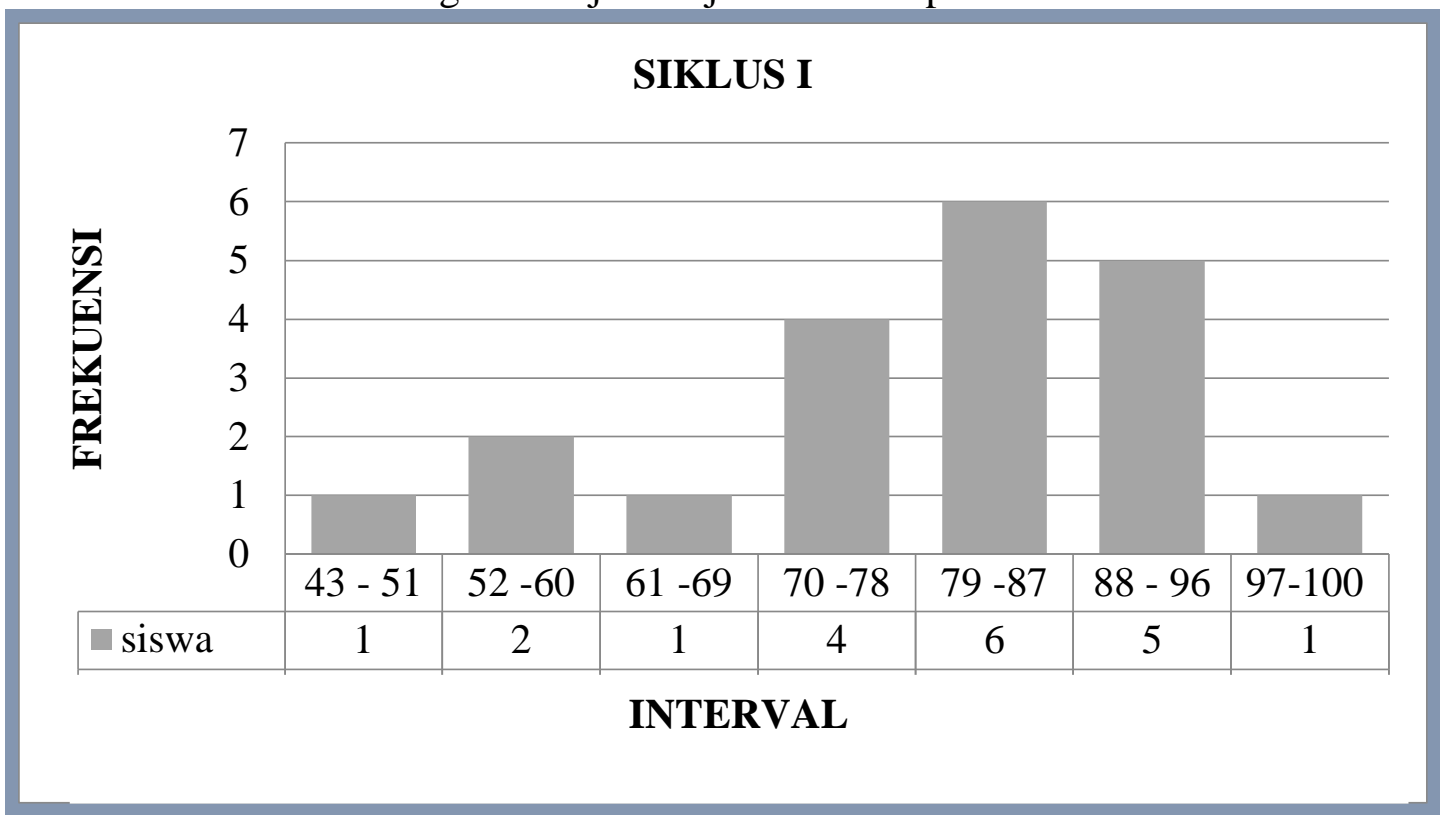

\section{Grafik 1. Hasil Tes Unjuk Kerja Siklus I}

Berdasarkan data yang diperoleh pada Siklus I menunjukan bahwajumlah siswa yang tuntas sebanyak 16 siswa atau (80\%), tidak tuntas sebanyak 4 siswa atau (20\%),

Dari tabel di atas, dapat disimpulkan bahwa anak kelas 5 SDN 018 Gerbang Sari dapat menuntaskan pembelajaran soal cerita tentang satuan waktu. Untuk lebih jelas mengenai peningkatan pembelajaran siswa dalam menggunakan metode CTL dari data siklus I table 2.

Tabel 2.Peningkatan Hasil Belajar Siswa Melalui Metode TPS

(ThinkPairShare)

\begin{tabular}{|c|c|c|}
\hline Kategoori & Siklus I & \multirow{2}{*}{ Ket } \\
\hline Tuntas & $16(80 \%)$ & \\
\hline Tidak Tuntas & $4(20 \%)$ \\
\hline Jumlah & $20(100 \%)$ \\
\hline
\end{tabular}


Dari tabel di atas, dapat disimpulkan secara klasikal siswa sudah tuntas belajar, karena siswa yang memperoleh nilai $\geq 75$ mencapai $80 \%$ lebih besar dari persentase yang dikehendaki yaitu $75 \%$. Jadi tidak perlu lagi ada tindakan siklus selanjutnya.

Berdasarkan dari data hasil penelitian, untuk mengetahui peningkatkan Hasil Belajar Soal Cerita Melalui Pendekatan Contextual Teaching and Learning (CTL) pada Siswa Kelas 5 Sekolah Dasar Negeri 018 Gerbang Sari dapat dilihat dari hasil penilaian yang dilakukan pada siklus I yakni diperoleh nilai maksimum adalah 98 dan nilai minimum adalah 43, sedangkan siswa yang tuntas sebanyak 16 siswa atau (80\%), dan tidak tuntas sebanyak 4 siswa atau $(20 \%)$.

Dari data diatas dapat dilihat bahwa pendekatan Contextual Teaching and Learning (CTL) dapat meningkatkan hasil belajar siswa kelas 5 SDN 018 Gerbang Sari. siswa termotivasi untuk belajar, karena siswa akan aktif dalam pembelajaran, memupuk rasa kerja sama dalam kelompok, hasil belajar dapat diukur dengan berbagai cara, dan menjadikan pembelajaran lebih menyenangkan dan bermakna bagi siswa.

Sesuai dengan pendapat Samrit (2007:1) pembelajaran CTL juga dapat membuat siswa menjadi aktif dan kreatif dan mampu berkomunikasi dengan baik dalam interaksi sosial. Karena dalam pembelajaran siswa dibiasakan bekerja dengan kemampuan otak dan fisik dalam sebuah kelompok. Dengan demikian siswa terlatih berkomunikasi dalam kelompok dan potensi-potensi yang ada dalam dirinya berkembang.

\section{SIMPULAN}

Berdasarkan hasil analisis dan pembahasan yang telah dilaksanakan dapat di simpulkan bahwa penerapan model pembelajaran kooperatif Tipe Numbered Head Together (NHT) dapat meningkatkan hasil belajar matematika siswa kelas VII SMP Negeri 3 Tapung Hilir itu terlihat dari 1) Aktivitas guru mengalami peningkatan, pada siklus I persentase rata-rata aktivitas guru adalah $66,7 \%$, meningkat sebanyak $16,6 \%$ menjadi $83,3 \%$ pada siklus II dan meningkat lagi pada siklus III sebanyak 10,5\% menjadi 93,8\%. Secara keseluruhan peningkatan aktivitas guru dari siklus I sampai siklus III mengalami peningkatan sebanyak $27,1 \%$. Aktivitas siswa mengalami peningkatan, pada siklus I persentase rata-rata aktivitas siswa adalah $60,4 \%$, meningkat sebanyak $16,7 \%$ menjadi $77,1 \%$ pada siklus II dan meningkat lagi pada siklus III sebanyak 12,5\% menjadi $89,6 \%$. Secara keseluruhan peningkatan aktivitas siswa dari siklus I sampai siklus III mengalami peningkatan sebanyak 29,2\% 2) Peningkatan hasil belajar siswa, pada skor dasar nilai ratarata siswa adalah 60,1 , pada siklus I meningkat menjadi 69,2, pada siklus II meningkat lagi menjadi 75,2 dan terus meningkat sampai siklus III menjadi 84,33 dan 3) Peningkatan persentase ketuntasan klasikal belajar siswa pada skor dasar 43,2\% meningkat menjadi $51,4 \%$ pada siklus I, pada siklus II meningkat lagi menjadi 64,9\% dan terus meningkat pada siklus III menjadi $83,9 \%$. Berdasarkan hasil penelitian, peneliti mengemukakan saran sebagai berikut uyaitu Bagi guru, di harapkan untuk menggunakan model pembelajaran kooperatif tipe Numbered Head Together (NHT) agar dapat meningkatkan hasil belajar matematika siswa dan Bagi sekolah, dapat dijadikan sebagai salah satu aternatif dalam pembelajaran agar dapat meningkatkan mutu pendidikan, terutama pada mata pelajaran matematika serta Bagi peneliti lainya penerapan model pembelajaran kooperatif Numbered 
Head Together (NHT) dapat dijadikan acuan atau dasar untuk menerapkannya pada mata pelajaran lainnya agar tercapainya hasil belajar yang lebih baik lagi.

\section{DAFTAR REFERENSI}

Ahmadi, Khairu, Iif dkk. 2011. Strategi Pembelajaran Sekolah Terpadu. Jakarta : Tim Prestasi Pustaka.

Aqip, Zainal dkk. 2011. Penelitian Tindakan Kelas. Bandung: CV. Yrama Widya. Arikunto, S. dkk. 2007. Penelitian tindakan kelas. Jakarta : Bumi Aksara.

Asma, Nur. 2006. Model Pembelajaran Kooperatif. Depdiknas

Bundu, Patta. 2006. Penilaian Keterampilan Proses dan Sikap Ilmiah. Depdiknas.

Daud,Damanhuri dan Alpusari,Mahmud. 2011. Pendidikan IPA Sekolah dasar. Pekanbaru : UR

Gimin, dkk. 2009. Model-Model Pembelajaran. Pekanbaru Cendikia insani.

Isjoni. 2010. Cooperatif learning."efektifitas pembelajaran kelompok". Bandung : Alfabeta.

Marsyam. 2013. Penerapan Pembelajaran Kooperatif Numbered Head Together (Nht) Dalam Meningkatan Hasil Belajar Matematika Pada Siswa Kelas V Sd Negeri 1 Pinrang. Universitas Negeri Makassar. Vol 2 No.2 . tersedia :http://diglib.unm.ac.id/gdl.di akses pada tanggal 17 Januari 2014.

Natuna, Daeng, Ayub. 2006. Belajar Teori Belajar Dalam Pembelajaran. Pekanbaru: UR

Purwanto. 2008. Evaluasi Hasil Belajar. Yogyakarta: Pustaka Belajar.

Ridwan, dkk. 2011. Pengantar Statistika. Bandung: Alfabeta

Riyanto, 2006. Penerapan. Tersedia: http : //www. sarjanaku. com/2010/10/ penerapan metode-inquiri-dalam. html (diakses tanggal 10 februari 2012)

Rusman. 2011."model-model pembelajaran” mengembangkan profesionalisme guru”. Jakarta : PT Raja Grafindo Persada.

Subarinah, Sri. 2006. Inovasi Pembelajaran Matematika Sekolah Dasar . Depdiknas

Syahrilfuddin, dkk. 2011. Penelitian Tindakan Kelas . Pekanbaru: Cendikia Insani.

Sudjana, N. 2003. Hasil Belajar Matematika. Tersedia : http: //tips-belajar-internet. Blogspot. Com/2009/08/Hasil-Belajar-Matematika. Html.

Sudjana, N. 2005. Penilaian Hasil Proses Belajar Mengajar. Bandung : PT Remaja Rosdakarya. 
Suprijono, Agus. 2009. Cooperative Learning. Yogyakarta: Pustaka Belajar.

Trianto. 2007. model-model pembelajaran inovatif berorientasi konstruktivistik. Jakarta : indonesia. 